\title{
Reforma educacional como barbárie social: economismo e o fim da autenticidade ${ }^{*}$
}

\section{Education reform as social barberism: economism and the end of authenticity}

\begin{abstract}
Stephen J. Ball ${ }^{* *}$
Resumo: Este trabalho aprofunda um artigo anterior sobre o papel da performatividade na mudança de prática profissional e das subjetividades do professor na educação. Argumenta-se que as tecnologias de comparação, mensuração e responsabilização, que atualmente proliferam nos sistemas educacionais no mundo todo não são simplesmente novas formas de monitorar resultados, mas estão ativamente alterando o que pretendem descrever. Elas mudam o significado do ensino e do que significa ensinar. Essas tecnologias de reforma estão alterando a forma como os professores pensam sobre o que fazem e como se relacionam com os colegas e com os alunos. Sociabilidade e coletividade estão sendo destruídas e substituídas por suspeição, competitividade, culpa e inveja, um novo repertório altamente carregado de emoções e relações sociais deformadas.
\end{abstract}

Palavras-chave: Performance. Subjetividade. Profissionalismo.

\begin{abstract}
This paper develops previous work on the role of performativity in changing professional practice and practitioner subjectivities in education. It is argued that the technologies of comparison, measurement and accountability, that are currently proliferating in education systems around the world, are not simply new ways of monitoring outcomes but are actively changing what they purport to describe. They change the meaning of teaching and what it means to teach. These technologies of reform are changing the ways that teachers think about what they do, relate to colleagues and to their students. Sociability and collectivity are being destroyed and are being replaced by suspicion, competition, guilt and envy, a new highly charged repertoire of emotions and deformed social relations.
\end{abstract}

Keywords: Performance. Subjectivity. Professionalism.

\footnotetext{
* Este trabalho representa uma maior elaboração das ideias esboçadas em Ball (2000) e Ball (2001). Originalmente, o artigo foi apresentado como Conferência na reunião da Scottish Educational Research Association - SERA Conference, de 2004. O artigo foi publicado no Scottish Educational Review (SER), v. 37, n. 1, 2005. A tradução foi autorizada pelo autor e pela editoria do Scottish Educational Review. Tradução de Silvia M. K. Breiby. Revisão de Luís Armando Gandin e Jefferson Mainardes. A Revista Práxis Educativa agradece o autor e ao editor pela autorização da tradução e publicação.

** Professor do Institute of Education/University of London. E-mail: <s.ball@ioe.ac.uk>
} 
"todos estes conceitos foram mal definidos, tornando-se difícil saber do que se está falando" (Foucault Live, 1996, p. 447).

\section{Introdução}

A minha preocupação aqui é com as consequências das recentes reformas educacionais para aquilo que comum e imprecisamente referimo-nos como profissionalismo do professor. No entanto, é extremamente difícil usar de sensatez para falar sobre o profissionalismo atualmente, em virtude do que Stronach e seus colegas (2002, p. 110), com razão, se referem como "redução metodológica, inflação retórica e excesso universalista" em que o conceito está inserido. Eu vou "confessar" a exploração e a perpetuação das partes da "epistemologia popular do profissionalismo" (PELS, 1999, p. 102), mas desejo dar a minha contribuição conceitual. Tentarei tratar o profissionalismo como "aquilo que é", uma forma de prática contextualizada, e fazer algumas reivindicações para uma versão normativa de um tipo de profissionalismo que não é nem "popular" e nem "pós". Também pretendo mostrar o profissionalismo como emblemático de algo mais, de certas mudanças gerais na natureza de, ou possibilidades de nossas vidas dentro do alto modernismo.

Quero também deixar claro que escrevo aqui, por experiência pessoal, de dentro ao invés de simplesmente sobre as práticas de profissionalismo. Esta é mais uma contribuição para a cacofonia de vozes que falam a, por e sobre os professores que estão competindo, com mais ou menos sucesso, para serem ouvidos.

Quero argumentar aqui que o profissionalismo está chegando ao seu final, está sendo desalojado de sua "existência precária, cintilante" - que está a caminho uma profunda mudança nas várias das "muitas forças independentes que condicionam a formação da identidade profissional de professores na prática" (DILLABOUGH, 1999, p. 390). Uma mudança tão profunda que no regime de "pós-Estado de Bem-Estar", o profissionalismo, como uma prática ética-cultural, parece não ter lugar, nem futuro. ${ }^{1} \mathrm{~A}$ minha narrativa, portanto, é de desespero, perda, dor e traição, embora não deva necessariamente ser lida como uma história de glória manchada - mais como um conto de fadas sobre a luta entre o menor de dois, ou mais, males.

Eu entendo que o profissionalismo, como uma categoria pré-reforma ou não-reformada, está baseado, pelo menos em parte - porque também possui características estruturais e organizacionais importantes - numa relação especial

\footnotetext{
${ }^{1}$ Vou deixar isso por enquanto, para que os outros proponham uma narrativa mais otimista de possibilidades para reconstrução neste mundo novo (GOLD et al., 2003; MOORE et al., 2002; STRONACH, 2002). Desejo assumir aqui a posição de que narrativas de esperança e a ontologia do "ainda não" (JONAS, 1984) de possibilidades, são distrações do imediatismo, o "real" de miséria e tormento.
} 
entre o que trabalha e seu trabalho, uma relação de compromisso localizada dentro de diálogos comunais e internos ${ }^{2}$. Isto é, dentro de uma reflexão moral - na tentativa de organizar a prática, por meio da tomada da decisão "certa", em um cenário moral que permite espaço para a incerteza moral, e a implantação do "conhecimento moral", conhecimento que, como Lambek (2000, p. 316) coloca, é tanto "prático" como "indefinido". O profissionalismo nestes termos está baseado na ambiguidade e no pluralismo. Conforme Bauman (1991, p. 51) coloca: "Somente o pluralismo devolve a responsabilidade moral pela ação ao seu portador natural: o indivíduo atuante". Isto é, o profissionalismo só tem sentido no quadro de uma racionalidade substantiva; tentativas de redefinir o profissionalismo dentro de um quadro dominado pela racionalidade técnica tornam o termo sem sentido. Com todos os perigos modernistas que existem, vou me referir ao profissional pré-reforma - como um profissional autêntico. Quando a autenticidade está baseada no valor da reflexão e na possibilidade sempre presente de indecisão ${ }^{3}$ - não que isso necessariamente tenha sempre acontecido na prática - mas uma vez que as possibilidades de reflexão moral, de diálogo e de indecisão são erradicadas, as possibilidades de profissionalização então estão, na verdade, erradicadas ${ }^{4}$. Desejo continuar argumentando que esta erradicação é conseguida, trazida para fora, pelos efeitos combinados das tecnologias da performatividade e do gerencialismo, que juntas, perfeita e extremamente, representam a busca modernista da ordem, da transparência, e da classificação - "uma consciência estimulada e movida pela premonição de inadequação" (BAUMAN, 1991, p. 9). Localizarei essa erradicação e suas conseqüências, ilustradas através de alguns dados, nas pessoas.

Um dos problemas ora existentes ao se abordar profissionalismo, é que em grande parte o uso corrente do termo, especialmente nos textos políticos e gerenciais, o significante apenas compreensível e o significado vagamente reconhecível foram divididos em partes. O que é diferentemente chamado de "novo profissionalismo" (McNESS; BROADFOOT; OSBORN, 2003, p. 248), "re-profissionalismo", "pós-profissionalismo" ou ainda, "profissionalismo pós-moderno" não são de modo nenhum profissionalismo (nos termos da minha normatividade). $\mathrm{Na}$ verdade, nos seus termos, o que eu poderia chamar

\footnotetext{
${ }^{2}$ Tenho de assumir minhas próprias ambivalências aqui - acerca de profissionalismo. Profissionais são tanto heróis quanto vilões na sociologia moderna.

${ }^{3}$ Dessa forma, eu não uso autenticidade aqui no exato sentido que Taylor (1981, p. 77) o faz - como "uma forma de vida mais auto-responsável" - mas não a excluo. Autenticidade para mim é a possibilidade e a validade de uma relação de reflexão entre o eu e as coletividades do mundo social. E isso certamente incorporaria a visão de Taylor (1981) das "práticas auto-centradas como o local de tensão inextinguível” que provém "do sentido de um ideal que não está sendo plenamente cumprido na realidade" (p. 76), e como ele continua dizendo "esta tensão pode se transformar em uma luta" (p. 77), e como na minha definição de profissionalismo, esta "será uma má notícia para quem esperava uma solução definitiva” (p. 77).

${ }^{4}$ Como parte do que Foucault (1970, p. 342) chama de "desaparecimento do homem".
} 
de profissionalismo pode até mesmo tornar-se "não profissional" (SMYTH et al., 2000, p. 85). Assim, se formos capazes de falar sobre profissionalismo, precisamos ter certeza de que sabemos o que queremos dizer com isto - é lógico, parte da resignificação de profissionalismo nos textos gerenciais, baseia-se na esperança de que não perceberemos que o que se entende por e se pratica, é diferente do que se entendeu e praticou antes. Os pontos-chave de diferença, ou no mínimo dois deles, são em primeiro lugar, que esses retrabalhos, estes "pósprofissionalismos" são, em última análise redutíveis a exogenamente gerados, seguidores de regras, e, em segundo lugar, que eles traduzem o profissionalismo numa forma de performance onde o que que conta como prática profissional depende do satisfazer às decisões fixas impostas externamente. Os critérios de qualidade ou de boa prática aqui são estanques e completos - em oposição "à necessidade de raciocínio moral e à incerteza adequada" (LAMBEK, 2000) como características definitivas da prática profissional. Colocando de outra maneira, o "pós-profissionalismo" está acima e oposto à "confiança" e à contingência. A eficácia só existe quando é medida e demonstrada, e circunstâncias locais somente se consideram como uma "desculpa" inaceitável para falha na entrega ou a falha de conformidade. No texto de Stronach e colegas (2002) dados são listados e em um ponto eles escrevem sobre os professores e enfermeiros que citam falando de "seu profissionalismo como algo que perderam" (STRONACH et al., 2002, p. 117). Parece-me que o "seu" na frase "seu profissionalismo", atinge o cerne de muitas das questões aqui. Pós-profissionalismo é profissionalismo de outra pessoa, não é o profissionalismo daquele que trabalha. Aquele que trabalha é tido como o responsável pelo seu desempenho, mas não pela avaliação sobre se o desempenho é "correto" ou "adequado", e sim se ele atende aos critérios da avaliação. Eles são "meros espectadores" (STRONACH et al., 2002, p. 115) ou "sujeitos desintegrados" (WEIR, 1997), dos quais exige-se "extrair-se da sua experiência social" (DILLABOUGH, 1999, p. 378) e esforçar-se para chegar a algum tipo de "instrumentalismo desengajado" (TAYLOR, 1989). Neste contexto, os professores perderam a possibilidade de exigir respeito, exceto em termos de performance. Eles têm sido objeto de um discurso de escárnio e não podem mais "falar por si mesmos" em debate público sobre ${ }^{5}$ a sua profissão. O sentimento de perda acima referido é, conforme Taylor (1991, p. 1) uma característica significativa do mal-estar da modernidade: "as pessoas sentem que algum declínio importante ocorreu". Um sentido que, novamente, ele relaciona com a "primazia da razão instrumental" (TAYLOR, 1991, p. 6) e um concomitante "desaparecimento de horizontes morais" (TAYLOR, 1991, p. 10). Bem, você pode querer me convencer de que, na Escócia pós-McCrone minha caracterização de "novo profissionalismo" é mal dirigida, muito Inglesa - mas antecipando esse argumento, gostaria de dizer algumas coisas. Primeiro, a minha interpretação da reforma aqui não se concentra em políticas únicas, como

${ }^{5}$ Em vez de "para" ou "em" educação. 
a de McCrone, e sim nos efeitos de conjuntos de políticas, como a de McCrone e as diretrizes curriculares, os testes, o controle da sala de aula, por exemplo. Como MacDonald (2004, p. 1543) faz em seu estudo etnográfico de uma escola primária da Escócia. Em segundo lugar, desejo desconectar tecnologias políticas de textos políticos e enfocar os efeitos próprios das tecnologias. Em terceiro lugar, embora não queira ignorar a importância das variações nacionais, a minha ênfase é sobre o que Menter e seus colegas chamam de "uma formação cultural performática global" (MacDONALD, 2004, p. 211) ${ }^{6}$.

\section{Performatividade e gerencialismo}

Após ter tentado esclarecer o uso do termo profissionalismo, talvez eu devesse agora fazer a mesma coisa com os meus outros termos-chave: performatividade e gerencialismo. Performatividade é uma tecnologia, uma cultura e um modo de regulação que emprega avaliações, comparações e demonstrações como meios de controle, desgaste, e mudança. As performances de indivíduos ou organizações servem como medidas de produtividade ou resultado, demonstrações de "qualidade", ou "momentos" de promoção ou inspeção. Eles defendem, encapsulam ou representam o mérito, a qualidade ou valor de um indivíduo ou organização num campo de avaliação, fazendo "silêncio audível" (BAUMAN, 1991, p. 5). A questão de quem controla o campo de avaliação é crucial, e um aspecto fundamental do movimento da reforma educacional global são as lutas situadas e as mudanças no controle do campo da avaliação e dos seus valores. Performatividade é o que Lyotard (1984, p. xxiv) chama de "os terrores - leves e pesados - do desempenho e eficiência - isto é, "seja operacional (ou seja, comensurável) ou desapareça". Isto surge, em boa parte, da "inclinação natural da prática moderna - a intolerância" (BAUMAN, 1991, p. 8). Para Lyotard, a performatividade encapsula a funcionalidade e instrumentalidade da modernidade e a mercantilização e exteriorização do conhecimento. Ela é alcançada através da construção e publicação de informações, indicadores e outros desempenhos institucionais e de materiais promocionais como mecanismos para animar, avaliar e comparar profissionais em termos de resultados, a unidade [de medida] para nomear, diferenciar e classificar - como por exemplo, através do "padrão de excelência” (TES, 09.11.04, p. 8). A performatividade, ou o que Lyotard também denomina, "controle de contexto" está intimamente entrelaçada com as possibilidades sedutoras de um determinado tipo de "autonomia" econômica (e não moral), a qual Lyotard denomina "autonomia coercitiva”, para tanto as instituições, e, em

\footnotetext{
${ }^{6}$ Enquanto Menter et al. (2004, p. 198) destacam "a abordagem McCrone é caracterizada por preocupações sobre o desenvolvimento profissional" em contraste com a pesada ênfase em "gestão de desempenho" da English Threshold Assessment's [Avaliação do Limiar Inglês], eu me pergunto até que ponto na prática o "desenvolvimento profissional" está separado das "pressões" (MacDONALD, p. 424) de um regime de desempenho em sala de aula.
} 
alguns casos, os indivíduos - tais como os diretores - ou devo dizer, líderes; a subjetividade "autônoma" desses indivíduos produtivos se tornou um recurso economico central no setor público empreendedor reformado.

Paralelamente e relacionado a isto, o gerencialismo tem sido o mecanismo-chave na/para a reforma política e reengenharia cultural do setor público nos países do Norte nos últimos 20 anos. O gerenciamento trabalha para incutir performatividade na alma do funcionário. Isto tem sido o principal meio "pelo qual a estrutura e cultura dos serviços públicos são reformulados ... [e] ... Agindo assim, procura introduzir novas orientações, remodela as relações de poder existentes e induz ao como e onde fazer as escolhas de políticas sociais" (CLARKE; COCHRANE; McLAUGHLIN, 1994, p. 4). Desempenha um papel-chave no desgaste dos regimes ético-profissionais que têm prevalecido nas escolas e na promoção de sua substituição por regimes de profissionais empreendedores competitivos. Isso envolve "processos de institucionalização e desinstitucionalização" (LOWNDES, 1997, p. 61) ao invés de uma mudança de "uma vez por todas"; é um desgaste contínuo composto de mudanças incrementais grandes e pequenas, que são muitas e díspares. Com o passar do tempo, o local de trabalho é "re-encantado", através de um emocionalismo instrumental e de uma liderança "carismática" pré-moderna renovada (HARTLEY, 1999).

Performatividade e gerenciamento, então, são duas das tecnologias políticas principais de reforma da educação. Tecnologias políticas implicam a implantação calculada de técnicas e artefatos para organizar forças humanas e capacidades em redes de poder em funcionamento. Vários elementos díspares são inter-relacionados nessas tecnologias envolvendo formas arquitetônicas, relações de hierarquia, processos de motivação e mecanismos de reforma ou terapia.

Quando empregadas em conjunto, essas tecnologias oferecem uma alternativa "eficaz" e politicamente atraente para a tradição de oferta educacional centrada no Estado e baseada na tradição do bem-estar público. Elas se colocam acima e contra as tecnologias mais antigas do profissionalismo e da burocracia. Elas se combinam para produzir o que a $\operatorname{OCDE}(1995$, p. 74$)$ chama de "um ambiente descentralizado", que "exige uma mudança por parte dos órgãos centrais de administração para estabelecer o quadro geral em vez da gerenciar as micro relações ... e mudanças de atitudes e comportamento em ambos os lados". Os diferentes papéis dos órgãos centrais de administração, neste novo ambiente, repousam, conforme a OCDE (1995, p. 75) colocou, sobre os "sistemas de controle" e a "produção de informações". Gerenciamento e performatividade são, portanto, as irmãs feias da reforma - elas empregam as disciplinas gêmeas da prova e do imperativo no esforço direcionado à ordem e à clareza. Estas são tecnologias incansáveis e orientadas para o futuro. Inerentes em seu dinamismo, há uma desvalorização contínua do presente - "o que o torna feio, abominável e 
insuportável” (BAUMAN, 1991, p. 11). Elas são definidas pelos estados de performance e perfeição que nunca podem ser alcançados, pela ilusão, que sempre se afasta, de um fim para mudar. Elas são amargas, implacáveis, incansáveis e impossíveis de se satisfazer.

Significativamente, então, as tecnologias políticas da reforma do setor público não são simplesmente veículos para a mudança técnica e estrutural das organizações, mas sim mecanismos para reformar os profissionais do setor públi$\mathrm{co}$, tais como os professores, para mudar o que significa ser professor, assistente social ou enfermeiro. Isto é, "a formação e reforma das capacidades e atributos do eu do [professor]” (DEAN, 1995, p. 567). A reforma não só muda o que fazemos. Ela também procura mudar quem somos, quem podemos nos tornar - a nossa "identidade social" (BERNSTEIN, 1996, p. 73). Ou seja, a reforma da educação trata "os poderes que têm sido exercidos sobre a existência subjetiva das pessoas e suas relações umas com as outras" (ROSE, 1989, p. ix). Assim, meu foco específico, não é principalmente nas estruturas e práticas, mas na reforma das relações e das subjetividades, e as formas da disciplina nova ou reinventada que esta origina. Dentro das políticas, tecnologias de reforma estão inseridas e fornecem novas identidades, novas formas de interação e novos valores.

Durante o processo de instalação dessas tecnologias nas organizações de serviço público, é importante o uso da nova linguagem para descrever papéis e relações; as organizações educacionais reformadas estão agora "povoadas" de recursos humanos que precisam ser geridas; a aprendizagem é re-traduzida como um "resultado da política custo-benefício"; a realização como um conjunto de "metas de produtividade", etc. Para ser importante, atualizado, precisamos falar sobre nós e os outros, pensar sobre nossas ações e relações em novas formas. Isto é o que Morley (2003) denomina “ventroloquismo". Estas linguagens nos falam, nos tornam um léxico de ordem e clareza. Novos papéis e subjetividades são produzidas enquanto professores e palestrantes são retrabalhados como produtores/fornecedores, empreendedores educacionais e gerentes e estão sujeitos à avaliação e a exames periódicos e à comparações de sua performance. Novas formas de disciplina são postas em prática pela competitividade, eficiência e produtividade. E novos sistemas éticos são introduzidos com base no interesse próprio, na pragmática e no valor performativo institucionais. Em cada caso, as tecnologias fornecem novos modos de descrição para o que fazemos e produzem novas restrições sobre as nossas possibilidades de ação. Não somos determinados, mas especialmente capacitados por elas. Este refazer pode significar aumento de nível e capacitação profissional para alguns, mas isso deve ser colocado por sobre e contra o potencial de "inautenticidade"; veja abaixo. O que acontece aqui é que a complexidade humana se reduz à forma mais simples possível - a uma classificação ou a um número numa tabela. 
No entanto, em tudo isso, mesmo constantemente tentados a falar sobre “o profissional", e de fato "o gestor" e "o líder" - estes não são, nem conjuntamente, nem individualmente identidades unitárias coerentes e fixas. Apesar das ambições da reforma, a natureza de propósito, o compromisso e a definição de papéis varia e tem sempre variado entre os indivíduos e é situacionalmente dependente. Configurações diferentes oferecem possibilidades e limites diferentes ao profissionalismo. E, na realidade, também na definição de profissionalismo a que me refiro, a autenticidade retrata o profissional como sempre "tornando-se", como "dinâmico e ambivalente" (STRONACH et al., 2002, p. 117), como um agente moral "sempre sensível à situação" que está "continuamente aprendendo" (DAWSON, 1994, p. 153), como gestor de dilemas e não simplesmente um eu promíscuo, "vazio", e pragmático.

Todavia, ao enfatizar as qualidades situacionais do profissionalismo, não pretendo sugerir que a novas instituições "performativas" são todas "do mesmo tipo" - conforme Lowndes $(1997$, p. 63) sugere, a tarefa da administração é construir "uma configuração relativamente estável de diferentes elementos institucionais". As configurações vão divergir entre as instituições até do mesmo tipo e seus elementos institucionais podem ser experienciados e respondidos de forma diferente pelos profissionais. Podem ainda haver lugares para se esconder, lugares em que a decisão "correta" ainda pode ser tomada dentro dos "fins diversos e complexos das organizações do serviço público" (LOWNDES, 1997, p. 62). Nós também poderemos até encontrar alguns dos "administradores com princípios" (GOLD; EVANS; EARLEY; HAPLIN; COLLARBONE, 2003) buscando resistir aos imperativos da "liderança bastarda" - como Wright (2001, p. 1) expressa - "a captura do discurso da liderança pelo projeto "gerencialista". Ou estou eu caindo no terreno pantanoso da esperança?

O que estou sugerindo aqui é que a combinação das reformas gerenciais e performativa têm grandes consequências na prática do ensino e na alma do professor - na "vida em sala de aula" e no mundo de imaginação do professor (EGAN, 1994) - aspectos de conduta diversos e específicos são reformulados e o locus de controle sobre a seleção de pedagogias e currículos é deslocado. A prática de sala de aula é cada vez mais "composta" de respostas às novas exigências externas. Os professores são considerados e caracterizados de novas maneiras; cada vez mais eles são considerados como técnicos pedagógicos.

Em essência, a performatividade é uma luta pela visibilidade. As informações são coletadas de forma contínua, gravadas e publicadas - muitas vezes na forma de tabelas comparativas de classificação. A performance também é monitorada por avaliações de pares, visitas e inspeções. Em tudo isso, "a violência ocorre em relação à concretude da" humanidade individual e da "especialidade" e os "processos humanos e sociais complexos são cada vez mais achatados em 
representações brutas que se conformarão à lógica da produção de mercadorias" (DE LISSOVOY; McLAREN, 2003, p. 133). Tornamo-nos "divíduos" (DELEUZE, 1992) - uma estatística de mercado, um item num banco de dados, parte de uma amostra. É o efeito generalizado de visibilidade e avaliação penetrando o modo como pensamos sobre a nossa profissão que faz o trabalho de performatividade. Não raramente os requisitos de tais sistemas trazem à existência práticas inúteis ou, de fato, prejudiciais, que, contudo, satisfazem aos requisitos de desempenho. Dentro do modelo de avaliações, comparações e incentivos relacionados ao desempenho, indivíduos e organizações farão o que for necessário para exceder ou para sobreviver. Em outras palavras, estas tecnologias políticas têm a "capacidade de re-moldar, na sua própria imagem, as organizações que controlam" (SHORE; WRIGHT, 1999, p. 570). Dúvidas constantes sobre quais avaliações podem estar em jogo em um momento qualquer, significa que todas e quaisquer comparações e requisitos de desempenho devem ser atendidos. Seleção e priorização tornam-se impossíveis e o trabalho e suas pressões se intensificam. E sempre, além apenas da fria racionalidade da performatividade está a indignação moral pública, construída em nosso nome na mídia, que visa difamar a "pior escola" e "professores insatisfatórios". Esta é a tenacidade "furiosa da crença em responsabilidade pessoal" (DE LISSOVOY; McLAREN, 2003, p. 134), que está profundamente inscrita na consciência moderna, e revelada no que Adorno (1995) chama "idealismo como raiva".

A performatividade depois reage profundamente no nosso senso de eu e em nossa autoestima. Ela convoca uma dimensão do estado emocional, apesar da aparência de racionalidade e objetividade - ela incide pesadamente sobre a culpa e a responsabilidade. Aqui o Bronwyn, um professor de $4^{a}$ série citado num relato sobre Reestructuring Schools, Reconstructing Teachers [Reestruturação de Escolas, Reconstrução de Professores], falando sobre a próxima inspeção da Ofsted (Office for Standards in Education, Children's Services and Skills).

Eu vou enfrentar isso, eu vou pensar nisto, vou fazer tudo que esperam que eu deva fazer e eu vou me curvar e vou apoiar o diretor até o fim e vou apoiar a escola até o fim. Eu não vou decepcionar ninguém. Mas secretamente dentro de mim mesmo, estou muito, muito brabo por estarmos sendo forçados a passar por isso, mas não estou muito certo com quem estou brabo. Com o Governo? Com a LEA [autoridade educacional locall? Deve ser com o Governo.

Vemos também a indefinição peculiar de performatividade. Estas avaliações têm uma vida própria. Nós somos responsáveis por e para com elas. Elas são exigências despersonalizadas que nos envolvem emocionalmente e nos confundem. MacDonald (2004, p. 429) descreve em seu estudo uma resposta semelhante por parte dos professores e seu sentido de "mudanças tais como 
as do Acordo pós-McCrone como algo "acontecendo" a "eles". Também aqui, novamente como MacDonald (2004, p. 426) descreve, existe de um lado, uma conformidade à forma, e por outro, uma resultante "dissonância entre ideologia e prática sobre o outro". E a raiva, o desânimo, a confusão e a dissonância, voltam-se para o interior e devem ser combatidas internamente. Como consequência, "qualquer resistência se torna aquela do indivíduo que procura integridade pessoal" - mas tal resistência internalizada pode ser extremamente estressante e prejudicial. (Veja também estudos de caso de dois professores primários, Osborne (1996)). Bronwyn assume tanto a responsabilidade de fazer o que parece ser necessário para apoiar o seu diretor e seus colegas, quanto lida com a sua raiva "secretamente interna". Muito do que a performatividade realiza em nós é feito por nós enquanto tentamos ser responsáveis para os outros.

\section{A violência da reforma}

Permitam-me citar mais dois professores de inglês da escola primária, primeiro a Elizabeth e depois a Cloe. Elizabeth está falando sobre a nova política de matemática de sua escola e a Cloe sobre o trabalho com alunos que farão um exame padronizado (Standard Assessment Tests - SATs).

Está nos clonando novamente. Eu redigi a norma de matemática da mesma forma que todos os outros, mas ela não expressa o modo como falo, penso ou acredito.

É completamente estranho para a minha forma de ensinar - testar e ensinar, ensinar para testar. No entanto, meu foco está naquilo realmente, e eu não dou a mínima para qualquer outra coisa. Se é isso que eles querem...

Ocorre, então, aqui o que Casey (1995) chama de "eus defensivos", subjetividades confusas e alienadas". . Subjetividades, e um "novo profissionalismo", que funcionam "de fora para dentro" (DAWSON, 1994), "em que a virtude é a consequência do seguimento de princípios prévios relativos à crença e conduta" (STRONACH et al., 2003, p. 113). O que Bernstein (2000, p. 1942) chama de "mecanismos de introjeção" segundo os quais "a identidade encontra sua essência em seu lugar em uma organização do conhecimento e prática", estão aqui sendo ameaçados ou substituídos por "mecanismos de projeção", ou seja, uma "identidade que é um reflexo de contingências externas" (BERNSTEIN, 2000, p. 1942) - A "clonagem" de Elizabeth. E respondendo a tudo isso, como forma de enfrentamento, a Cloe está desistindo da autenticidade, da crença e do compromisso, ela vai se concentrar em fazer o que é necessário, o que se exige dela, e não o que ela considera certo.

${ }^{7}$ A subjetividade são "padrões pelos quais contextos experienciais e emocionais, sentimentos, imagens e memórias são organizados para formar a auto-imagem de alguém, o sentido de si e dos outros, e nossas possibilidades de existência". (DE LAURETIS, 1986, p. 5). 
Para professores individuais de pré-reforma ou não-reformados lutando com a autenticidade, uma espécie de esquizofrenia de valores se experiencia quando o compromisso e a experiência na prática têm que ser sacrificados em favor da impressão e da performance. Aqui existe o "dividir" potencial entre os julgamentos dos próprios professores sobre "boas práticas" e as "necessidades" dos alunos, de um lado, e os rigores da performance, do outro. Há uma "disjunção entre a política e a prática preferida" (NcNESS; BROADFOOT; OSBORN, 2003 , p. 255). Esses professores experimentam uma "consciência bifurcada" (SMITH, 1987), um "eu-segmentado" (MILLER, 1983), ou a luta com "emoções proscritas" (JAGGAR, 1989), enquanto tentam corresponder a e gerenciar "as contradições de crença e expectativa” (ACKER; FEUERVERGER, 1997 apud DILLABOUGH, 1999, p. 382) que estão inseridas nas posições de sujeito de autenticidade e de reforma. Conforme expresso por Bauman (1991, p. 197) esta é "a privatização da ambivalência", que, "lançada sobre os ombros do indivíduo, exige uma estrutura óssea que poucos indivíduos possuem" - estresse, doença e esgotamento nervoso, são frequentemente o resultado disso. Na medida em que se apegam às suas "emoções proscritas", professores como os citados acima e abaixo, arriscam serem "construídos fora desta visão dominante do profissional, apesar das exigências colocadas sobre eles para se conformarem a ela" (DILLABOUGH, 1999, p. 382). Autenticidade e performatividade se chocam e conflitam - especialmente, como McNess, Broadfoot e Osborn (2003, p. 255-256) descobriram, para os professores na Inglaterra. Frank afirma:

Eu amo o contato com as crianças e quando eu digo papelada, eu não estou falando sobre a dar notas ou preparação. É a interferência, não do diretor, mas dos órgãos públicos e privados... Muito do prazer vai embora com ela... Estamos tão ocupados avaliando os alunos que estamos esquecendo de ensiná-los.

Frank está realmente tendo dificuldade em se ver como aquele tipo de professor que simplesmente produz performances - a sua própria e a dos seus alunos. Seus comprometimentos com o ensino e seu prazer de ensinar, suas razões para se tornar e permanecer como professor, parecem não ter lugar na sala de aula reformada. Ele se vê como "um professor desprovido de conexões significativas com aqueles a quem deve educar" (DILLABOUGH, 1999, p. 379). O que Smyth e Dow et al. (2000, p. 140) chamam de "primazia das relações de cuidado no trabalho com alunos e colegas", ou o que McNess, Broadfoot e Osborn (2003, p. 246) descrevem como "um modelo sociocultural que reconheceu e incluiu os aspectos emocionais e sociais necessários para uma abordagem mais centrada no aluno" não têm lugar no mundo produtivo da performatividade. A eficácia está comprometendo o afetivo (McNESS; BROADFOOT; OSBORN, 2003). A história de Frank não é única no Reino Unido, já que o regime de 
performatividade tem aumentado o número de professores que saem do sistema de ensino. Parece que as preocupações atuais relacionadas com a baixa disposição dos professores e, em alguns contextos, o problema de subcontratação para o ensino, baseiam-se, pelo menos em parte, no fato de os professores terem que desistir dos seus compromissos autênticos e crenças sobre o ensino em face de reforma (McNESS; BROADFOOT; OSBORN, 2003, p. 255). Professores como Frank e Cloe e Elizabeth não são mais estimulados a ter uma justificativa pessoal para a prática, uma narrativa sobre eles mesmos no que se refere à importância daquilo que fazem, em contraposição; ao invés disso, exige-se deles que produzam e "melhorem" os resultados e desempenhos mensuráveis; o que é importante é o que funciona para alcançar esses fins. Isto leva ao que Acker e Feuerverger (1996) chamam de "fazendo bem e sentindo-se mal", o que também pode ser considerado uma versão do que Moore, Edwards, Halpin e George (2002, p. 554) chamam de "pragmatismo contingente" - "ou seja, um sentimento de conscientemente estar em estado de ajuste altamente imposto".

Há três versões de prática (não) autêntica aqui: uma em relação a si mesmo, o sentido próprio do que é certo; nas relações com os seus alunos, quando um compromisso com a aprendizagem é substituído pelas metas de desempenho; e nas relações com os seus colegas professores, quando a luta e o debate - ao que De Lissovoy e McLaren (2003, p. 134), na sua versão de autenticidade, se referem como "uma relação dialética verdadeira... entre os momentos individuais... e coletivos de ser" - são substituídos pela conformidade e o silêncio. Esta esquizofrenia estrutural individual dos valores e dos fins, o potencial para a não autenticidade e a falta de significado constituem, cada vez mais, uma experiência cotidiana para todos nós. As atividades da nova intelligentsia técnica e da gestão conduzem à performatividade para a rotina das práticas dos professores e para relações sociais entre professores. Elas fazem a gestão, onipresente, invisível, inevitável - parte de e inserida em tudo que fazemos. Cada vez mais, escolhemos e avaliamos as nossas ações e elas são avaliadas por outros baseadas em nossa contribuição para o desempenho organizacional, materializadas em termos de resultados mensuráveis. As crenças não são mais importantes - o resultado é o que conta. As crenças são parte de um velho discurso, cada vez mais deslocado. Em outras palavras, os professores assim como o Frank e a Elizabeth procuram se apegar aos conhecimentos sobre si e sobre sua prática que divergem dos das categorias dominantes. Estes são vistas agora, expresso por Foucault, como "conhecimentos inadequados para a sua tarefa... conhecimentos ingênuos... conhecimentos desqualificados" (FOUCAULT, 1980, p. 81-82). Um novo tipo de professor e novos tipos de conhecimentos são "convocados" pela reforma educacional - um professor que pode maximizar a sua performance, que pode descartar princípios irrelevantes, ou compromissos sociais fora de moda, 
para quem a excelência e a melhoria são o motor propulsor de sua prática. Sob um regime de performatividade, "a identidade depende da facilidade em projetar organização discursiva/práticas movidas por contingências externas" (BERNSTEIN, 2000, p. 1942). Estas novas identidades pós-profissionais são muito poderosas, mas também muito frágeis e há momentos, conforme indicado acima, em que elas se tornam insustentáveis. Este tipo de "pós-profissionalismo" é comumente articulado em termos de colegialidade aumentada, mas uma colegialidade obtida pela individuação e, na verdade, pela competição, e fixada em relação às visões de liderança e aos objetivos corporativos - uma colegialidade contida (HARGREAVES, 1991).

Inseridos em quase todos os exemplos citados, verifica-se um conjunto de dualismos ou tensões - e, como tal, precisamos suspeitar bem deles (MacLURE, 2003, p. 9-10). Eles são as tensões entre crença e representação. Por um lado, os professores estão preocupados com o fato de que o que fazem não será representado por nem valorizado dentro das métricas de responsabilização e, do outro lado, com o fato de que essas métricas, se levadas a sério, distorcerão ou "tornarão oca" a sua prática. Paralelamente a estas existe uma tensão adicional, já indicada, entre performances métricas e relacionamentos autênticos e com propósito $^{8}$. Isto está diretamente ligado à definição do que significa ensinar.

Crucialmente, como já apontado, estas novas formas de regulação institucional e de sistema possuem ambas uma dimensão social e interpessoal. Elas penetram as nossas interações mundanas diárias de tal modo que a interação dos seus aspectos ligados ao coletivo e ao disciplinar torna-se realmente muito confusa. Neste aspecto há uma possibilidade real de que as relações sociais autênticas sejam substituídas por relações performativas em que as pessoas são valorizadas somente pela sua produtividade. $O$ valor delas como pessoa está erradicado. Um exemplo do que De Lissovoy e McLaren (2003, p. 133) chamam de "violência do apagamento". O mesmo pode ocorrer nas relações professor-aluno, em que os desempenhos dos alunos são vistos principalmente em termos do seu impacto sobre a reputação institucional - por exemplo, dentro do que Gillborn e Youdell (2001, p. 74) chamam de "Economia de A a C" que, eles afirmam, "captar algo da natureza despersonalizada dos processos em que professores e alunos sentem-se presos em armadilhas". No entanto, estas não são simplesmente coisas feitas para nós, como nos regimes de poder anteriores. Estas são coisas que fazemos a nós mesmos e aos outros. $\mathrm{O}$ que percebemos aqui é um conjunto especial de "práticas através das quais agimos sobre nós mesmos e uns sobre os outros, a fim de nos tornarmos determinados tipos de

\footnotetext{
${ }^{8}$ Embora, como vários comentadores têm destacado, não é impossível conceber um sistema de métricas benignas ou progressivas, relacionado à redução das desigualdades sociais, por exemplo. A questão é se a forma e a substância da performatividade podem ser separadas. Eu tenho minhas dúvidas.
} 
ser" (ROSE, 1992, p. 161). Mahony e Menter et al. (2004) abordam estas questões e os impactos emocionais da reforma sobre os professores em seu relato sobre o pagamento relacionado ao desempenho e citam este professor:

Quando comecei a ensinar era uma profissão muito legal ... você realmente acabava conhecendo as crianças para quem lecionava. Mas agora, é quase como se, por estarmos sob esse enorme estresse e tensão, nós nos tornássemos imunes a isso e acabássemos levando esse estresse aos alunos. Estamos formando crianças muito estressadas ... Eu não considero isto saudável. (Professor $1 / \mathrm{f}$, Seamill Secondary).

\section{Dois discursos - e as possibilidades de estabelecer uma relação diferente consigo mesmo}

Um complexo de discursos sobrepostos, agonísticos e antagonísticos enxameiam e fervilham em torno de um profissional do futuro ou de outrora neste cenário da reforma ${ }^{9}$. Mas estes discursos podem ser resumidos, com algum grau de simplificação, em dois. Um dominante e um atualmente muito subordinado (veja, por exemplo, FULLAN; HARGREAVES, 1992 e GRIMMETT; NEUFELD, 1994). O primeiro engloba o "reformado ou pósprofissional", ou nas palavras de Laughlin (1991), o profissional "colonizado", que é responsável, e, sobretudo, generica e principalmente orientado para os indicadores de desempenho, competitividade, comparação e capacidade de resposta, etc. Aqui o cálculo frio e os valores extrínsecos predominam. Este é o arquétipo do profissional "pós-moderno" definido pela superficialidade, flexibilidade, transparência e representado dentro do espetáculo - dentro de performances. Assim como a instituição performativa o "pós-profissional" também é concebido como simplesmente o que responde às exigências externas e a metas específicas, munido de métodos formalistas apropriados para toda eventualidade - um "especialista sem espírito" nas palavras de Weber. O seu "profissionalismo" é inerente à vontade e a capacidade de se adaptar às necessidades e vicissitudes da política. Este é um profissional que é essencialmente dispensável e insubstancial; que está "desengajado" (WEIR, 1997) e um "objeto de conhecimento" (DILLABOUGH, 1999, p. 387). Um profissional cuja ação social é passada de modo adiafórico como expressou Bauman. Essa ação social "não é nem boa e nem má, mensurável em relação aos critérios técnicos (orientada para um propósito ou processo), mas não com critérios morais ... ela torna ineficaz a responsabilidade moral pelo Outro" (BAUMAN, 1993, p. 125).

\footnotetext{
${ }^{9}$ E como eu sugeri na prática, alguns professores como sujeitos sociais vivem ambos os discursos e lutam para lidar com a sua discordância.
} 
O último, o subordinado, é um discurso muito modernista, um discurso subavaliado e subestimado expresso num registro muito diferente, que interpola o que eu chamei de "profissional autêntico" ou (talvez) "profissional reorientado", que absorve e aprende com, mas não é fundamentalmente reformado pela reforma. Esse profissional existe "num espaço de preocupações" (TAYLOR, 1989, p. 51). O trabalho do "professor autêntico" envolve "questões de cunho moral, de investimento emocional e de consciência, habilidade e acuidade política" (HARGREAVES, 1994, p. 6). Autenticidade é ensinar tendo um coração "emocional" (WOODS, 1996), ou como afirma Hargreaves, o ensino, neste sentido, é sobre o desejo, porque "o ensino sem desejo, torna-se árido e vazio, ele perde o seu significado" (HARGREAVES, 1994, p. 12). O significado é fundado tanto sobre um compromisso pessoal - motivação - e uma linguagem moral compartilhada. De acordo com Charles Taylor "a autenticidade... requer (i) abertura a horizontes de significado... e (ii) uma auto-definição em diálogo" (TAYLOR, 1991, p. 66).

Aqui a prática profissional "não é somente determinada pela sua própria narrativa, mas... também moldada por relações sociais e estruturais de dentro e de fora...” (DILLABOUGH, 1999, p. 37). Como coloca Dillabough (1999, p. 393) "os professores, como indivíduos autênticos, trazem à prática de ensino (a história, a narrativa, a subjetividade, o posicionamento)". Professores autênticos sabem a sua posição em relação a um campo metafórico de disciplina autogovernada, mas necessariamente não ficam parados. Este campo fornece uma base de diálogo, reflexão e debate, um espaço público para o discurso moral e crítico. Ele não lhes diz o que fazer. Ele lhes fornece uma linguagem para pensar sobre o que eles fazem e para refletir sobre seu trabalho e o trabalho dos outros numa relação de sujeitos ativos. Eles agem dentro de um conjunto de dilemas situados e confusões desordenadas - para os quais frequentemente não há soluções satisfatórias, simples, ou únicas. Eles aprendem a conviver com a ambivalência. Profissionalismo aqui é uma questão de atuar na incerteza e aprender com as consequências - uma "profissão de aprendizagem" (NIXON et al., 1997). É uma questão de "descobrir como agir moralmente num contexto educacional incerto e em constante mudança” (GRIMEETT'; NEUFELD, 1994, p. 229). Eles discutem e chegam a um comum acordo, planejam e agem espontaneamente, e improvisam dentro e através de expectativas e papéis contraditórios; a criatividade e a imaginação são importantes; "a própria professora é um recurso na gestão dos problemas da prática educacional” (LAMPERT, 1985, p. 194) ${ }^{10}$ é uma mistura de arte e intuição (HUMPHREYS; HYLAND, 2002, p. 9). Claramente, esse tipo de linguagem e imagística vai de encontro tanto à calculabilidade e racionalidade

\footnotetext{
${ }^{10}$ Como com as escolas, os professores também serão posicionados de maneira diferente para resistir às pressões de reforma, ou para "reter" uma perspectiva "autêntica".
} 
da reforma quanto às falsas performances comemorativas de excelência e qualidade $^{11}$. Tudo isso pode ser traduzir em algo como o que Nixon et al. (1997, p. 25) chamam de "profissionalismo emergente" que pode ser definido com os valores e práticas do "acordo" e do chegar a um "acordo".

Salas de aula "autênticas" e "reformadas" podem ser lugares bem distintos de estar, tanto para o aluno quanto para o professor ${ }^{12}$. Também desejo esclarecer bem aqui que a professora "autêntica" não é simplesmente aquela professora que havia antes da reforma. Não estou simplesmente tentando evocar um "antecedente imaginário"; embora alguns dos professores citados remetam aos "melhores tempos" e, evidentemente, a crítica a professores que serve de base ao "pós-profissionalismo" frequentemente negocie pesado, com certeza no Reino Unido, sobre uma história de ensino revisionista que erradica "contra memórias" (BARBER; SEBBA, 1999), é um exemplo impressionante de tal revisionismo). No entanto, meu ponto é que a autenticidade é um discurso diferente de profissionalismo, não simplesmente um antigo discurso.

\section{Referências}

ADORNO, T. Negative dialectics. New York: Continuum, 1995.

ACKER, S.; FEUERVERGER, G. Doing Good and Feeling Bad: the work of women university teachers. Cambridge Journal of Education, v. 26, n. 3, p. 401-422, 1996. DOI: 10.1080/0305764960260309

BALL, S. J. Performativities and fabrications in the education economy: towards the performative society? Australian Educational Researcher, v. 27, n. 2, p. 1-23, 2000. DOI: 10.1007/BF03219719

. Performativities and fabrications in the education economy: towards the performative society. In: GLEESON, D.; HUSBANDS, C. T. The performing school: managing teaching and learning in a performance culture. London: Routledge Falmer, 2001.

BARBER, M.; SEBBA, J. Reflections on progress towards a world class education system. Cambridge Journal of Education, v. 29, n. 2, p. 183-193, 1999. DOI: 10.1080/0305764990290202

BAUMAN, Z. Modernity and ambivalence. Oxford: Polity Press, 1991.

Mortality, immortality and other life strategies. Stanford: Stanford University Press, 1992.

Postmodern ethics. Oxford: Blackwell, 1993.

BERNSTEIN, B. On the classification and framing of educational knowledge. In: YOUNG, M. (Ed.). Knowledge and Control. London: Collier Macmillan, 1971.

\footnotetext{
${ }^{11}$ A questão da linguagem, e mais geralmente do discurso, provavelmente nunca foi mais importante no campo da educação. Professores educadores e os próprios professores também precisam estar muito, muito cientes dos vocabulários em uso enquanto responsáveis pelo ato de ensinar.

${ }^{12}$ Este talvez levanta a questão se encontraremos ou não professores "autênticos" em salas de aula "reformadas".
} 
Pedagogy symbolic control and identity. London: Taylor and Francis, 1996.

Official Knowledge and Pedagogic Identities: the politics of recontextualising. In: BALL, S. J. (Ed.). The Sociology of Education: major themes. London: Routledge Falmer, 2000.

CASEY, C. Work, self and society after industrialisation. London: Routledge, 1995.

CLARKE, J.; COCHRANE, A.; McLAUGHLIN, E. Managing social policy. London: Sage, 1994.

DAWSON, A. J. Professional codes of practices and ethical conduct. Journal of Applied Philosophy, v. 11, n. 2, p. 145-153, 1994. DOI: 10.1111/j.1468-5930.1994.tb00104.x

DE LISSOVOY, N.; McLAREN, P. Educational 'accountability' and the violence of capital: a Marxian reading. Journal of Education Policy, v. 18, n. 2, p. 131-143, 2003. DOI: 10.1080/0268093022000043092

DEAN, M. Governing the unemployed self in an active society. Economy and Society, v. 24, n. 4, p. 559-583, 1995. DOI: 10.1080/03085149500000025

DILLABOUGH, J.-A. Gender politics and conceptions of the modern teacher: women, identity and professionalism. British Journal of Sociology of Education, v. 20, n. 3, p. 373-394, 1999. DOI: 10.1080/01425699995326

DU GAY, P. Consumption and identity at work. London: Sage. 1996.

EDWARDS, P. Late twentieth century workplace relations: class struggle without classes. In: CROMPTON, R. et al. Renewing class analysis. Oxford: Blackwell, 2000.

EGAN, K. Tools for enhancing imagination in teaching. In: GRIMMETT, P. P.; NUEFELD, J. (Eds.). Teacher development and the struggle for authenticity. New York: Teachers College Press, 1994.

FOUCAULT, M. The order of things: an archaeology of the human sciences. London: Tavistock, 1970.

Discipline and punish. New York: Pantheon Press, 1977.

Discipline and punish. Harmondsworth: Peregrine, 1979a.

. On governmentality. Ideology and Consciousness, v. 6, n. 1, p. 5-22, 1979 b.

. Two lectures: power/knowledge. Ed/trans C. Gordon. London: Longman, 1980.

Foucault live: collected interviews, 1961-84. Edited by S. Lotringer. New York: Semiotext(e), 1996.

FULLAN, M.; HARGREAVES, A. Teacher development and educational change. Lewes: Falmer, 1992.

GIDDENS, A. Modernity and self-identity. Cambridge: Polity, 1991.

GILLBORN, D.; YOUDELL, D. Intelligence, 'ability' and the rationing of education. In: DEMAINE, J. (Ed.). Sociology of Education Today. London: Palgrave, 2001.

GOLD, A.; EVANS, J.; EARLEY, P.; HALPIN, D.; COLLARBONE, P. Principled principals? Values driven leadership: evidence from ten case studies of 'outstanding' school leaders. Educational Management Administration \& Leadership, v. 31, n. 2, p. 127-138, 2003. DOI: $10.1177 / 0263211 \mathrm{X} 030312002$ 
GRAY, J.; HOPKINS, D. et al. Improving schools: performance and potential. Buckingham: Open University Press, 1999.

GRIMMETT, P. P.; NEUFELD, J. (Eds.). Teacher development and the struggle for authenticity. New York: Teachers College Press, 1994.

HARGREAVES, A. Contrived collegiality: the micropolitics of teacher collaboration. In: BLASÉ, J. (Ed.). The politics of life in schools: power conflict and cooperation. London: Sage, 1991.

Changing teachers, changing times. London: Cassell, 1994.

HARTLEY, D. Marketing and the 're-enchantment' of school management. British Journal of Sociology of Education, v. 20, n. 3, p. 309-323, 1999. DOI: 10.1080/01425699995281

HUMPHREYS, M.; HYLAND, T. Theory, practice and performance in teaching: professionalism, intuition and jazz. Educational Studies, v. 28, n. 1, p. 5-15, 2002. DOI: $10.1080 / 03055690120090343$

JAGGAR, A. Love and knowledge: emotion in feminist epistemology. In: JAGGAR, A.; BORDO, S. (Eds.). Gender/Body/Knowledge. New Brunswick: Rutgers University Press, 1989.

JEFFREY, B.; WOODS, P. Testing teachers: the effect of school inspections on primary teachers. London: Falmer Press, 1998.

JONAS, H. Philosophical essays: from ancient creed to technological man, englewood cliffs. NJ: Prentice-Hall, 1974.

LAMBEK, M. The anthropology of religion and the quarrel between poetry and philosophy. Current Anthropology, v. 41, n. 3, p. 309-320, 2000. DOI: 10.1086/300143

LAMPERT, M. How do teachers manage to teach? Perspectives on problems in practice. Harvard Educational Review, v. 55, n. 2, p. 178-194, 1985.

LAUGHLIN, R. Can the information systems for the NHS internal market work? Public Money and Management, v. 11, n. 3, p. 37-41, 1991. DOI: 10.1080/09540969109387666

LAVY, V. Evaluating the Effect of Teachers' Performance Incentives on Pupil Achievement. Jerusalem: Hebrew University of Jerusalem, 2001. (Unpublished paper).

LAZEAR, E. P. Paying teachers for performance: incentives and selection. Hoover Institution and Graduate School of Business: Stanford University, 2001. (Unpublished paper).

LOWNDES, V. Change in public service management: new institutions and new managerial regimes. Local Government Studies, v. 23, n. 2, p. 42-66, 1997. DOI: $10.1080 / 03003939708433864$

LYOTARD, J. F. The postmodern condition: a report on knowledge. Manchester: Manchester University Press, 1984. v. 10.

MacDONALD, A. Collegiate or compliant? Primary teachers in post-McCrone Scotland. British Educational Research Journal, v. 30, n. 3, p. 413-433, 2004. DOI: 10.1080/01411920410001689715

MacLURE, M. Discourse in educational and social research. Buckingham: Open University Press, 2003. 
MAHONY, P.; MENTER, I. et al. The emotional impact of performance-related pay on teachers in England. British Educational Research Journal, v. 30, n. 3, p. 435-456, 2004. DOI: $10.1080 / 01411920410001689724$

McNESS, E.; BROADFOOT, P.; OSBORN, M. Is the effective compromising the affective? British Educational Research Journal, v. 29, n. 2, p. 243-257, 2003. DOI: 10.1080/0141192032000060966

MENTER, I.; MAHONY, P.; HEXTALL, I. Ne'er the twain shall meet?: modernizing the teaching profession in Scotland and England. Journal of Education Policy, v. 19, n. 2, p. 195-214, 2004. DOI: 10.1080/0144341042000186336a

MILLER, J. L. The resistance of women academics: an autobiographical account. Journal of Educational Equity and Leadership, v. 3, n. 2, p. 101-109, 1983.

MULLER, J. The well-tempered learner: self-regulation, pedagogical models and teacher education policy. Comparative Education, v. 34, n. 2, p. 177-193, 1998. DOI: 10.1080/03050069828261

NIXON, J.; MARTIN, J. et al. Towards a learning profession: changing codes of occupational practice within the new management of education. British Journal of Sociology of Education, v. 18, n. 1, p. 5-28, 1997. DOI: 10.1080/0142569970180101

OECD. Governance in transition: public management reforms in OECD countries. Paris: Organisation for Economic Co-operation and Development, 1995.

OSBORNE, M. Identity, career and change: a tale of two teachers. In: CROLL, P. (Ed.). Teachers, pupils and primary schooling: continuity and change. London: Cassell, 1996.

PELS, P. Professions of duplexity: a prehistory of ethical codes in anthropology. Current Anthropology, v. 40, n. 2, p. 101-136, 1999. DOI: 10.1086/200001

PETERS, T.; WATERMAN, R. In search of excellence. London: Harper Row, 1982.

ROSE, N. Governing the soul: the shaping of the private self. London: Routledge, 1989. Governing the enterprising self. In: HEELAS, P.; MORRIS, P. (Eds.). The Values of the Enterprise Culture. London: Routledge, 1992.

Governing “advanced” liberal democracies. In: BARRY. A.; OSBORNE, T.; ROSE, N. (Eds.). Foucault and political reason: liberalism, neo-liberalism and rationalities of government. London: UCL Press, 1996.

RYAN, B. Competency-based reforms to Australian teaching: the last rites for social democracy. Journal of Education Policy, v. 13, n. 1, p. 91-113, 1998. DOI: 10.1080/0268093980130106 SHORE, C.; WRIGHT, S. Audit culture and anthropology: neo-liberalism in British higher education. The Journal of the Royal Anthropological Institute, v. 5, n. 4, p. 557-575, 1999. DOI: $10.2307 / 2661148$

SIKES, P. Teachers' lives and teaching performance. In: GLEESON, D.; HUSBANDS, C. The performing school: managing teaching and learning in a performance culture. London: Routledge Falmer, 2001. 
SMYTH, J. et al. Teachers' work in a globalising economy. London: Falmer Press, 2000.

STRONACH, I. et al. Towards an uncertain politics of professionalism: teacher and nurse identities in flux. Journal of Education Policy, v. 17, n. 1, p. 109-138, 2002. DOI: 10.1080/02680930110100081

TAYLOR, C. Sources of the self: the making of the modern identity. In: TAYLOR, C. (1991) The malaise of modernity. Cambridge, MA: Harvard University Press, Toronto, Anansi, 1989.

The ethics of authenticity. Cambridge: Harvard University Press, 1991.

WEIR, A. Sacrificial logics: feminist theory and the critique of identity. New York: Routledge, 1997.

WILLMOT'T, H. Postmodernism and excellence: the de-differentiation of economy and culture. Journal of Organisational Change and Management, v. 5, n. 1, p. 58-68, 1992. DOI: $10.1108 / 09534819210010980$

Strength is ignorance; slavery is freedom: managing culture in modern organizations. Journal of Management Studies, v. 30, n. 4, p. 515-552, 1993. DOI: 10.1111/j.14676486.1993.tb00315.x

WOODS, P. Researching the art of teaching: ethnography for educational use. London: Routledge, 1996.

WOODS, P.; JEFFREY, B. et al. Restructuring schools, reconstructing teachers. Buckingham: Open University Press, 1997.

WRIGHT, N. Leadership, 'bastard leadership' and managerialism: confronting twin paradoxes of the Blair education project. Educational Management Administration \& Leadership, v. 29, n. 3, p. 275-290, 2001. DOI: 10.1177/0263211X010293003

Principled 'bastard' leadership? A rejoinder to Gold, Evans, Earley, Halpin and Collarbone. Centre of Educational Studies, University of Hull, 2003.

Recebido em 10/04/2011

Aceito em 17/11/2011 